\title{
The use of furans in natural product syntheses*
}

\author{
Henry N. C. Wong, † Pei Yu and Chung-Yan Yick \\ Department of Chemistry, The Chinese University of Hong Kong, Shatin, \\ New Territories, Hong Kong
}

\begin{abstract}
Syringolides 1 (1) and 2 (2) in optically pure forms were prepared from the chiral butenolide 9, which in turn was obtained from tri-n-butylstannylfuran (8). Attempts are also being made towards the synthesis of sesquiterpenoid lactones making use of 3-methyl-4trimethylsilylfuran (17) as a pivotal precursor.
\end{abstract}

Syringolide 1 (1) and syringolide 2 (2) are microbial elicitors produced through the action of a avirulence gene (avrD) of Pseudomonas syringae pv. tomato. These unusual metabolites function as specific molecular signal molecules that are able to induce hypersensitive defence response in soybean plants. [1]

Scheme 1 indicates the biogenetic association between the syringolides and their relevant metabolites, namely secosyrin $1(\mathbf{3})$, secosyrin $2(\mathbf{4})$, syributin $1(\mathbf{5})$ and syributin $2(\mathbf{6})$. It is certain now that the syringolides would experience a retro-Claisen cleavage reaction to furnish the secosyrins, which in turn would lead to the syributins by way of a retro-Michael reaction and a subsequent 1,3-acyl migration.

The intriguing tricyclic frameworks of $\mathbf{1}$ and $\mathbf{2}$ have made them target molecules in hot pursuits, as can be shown by the fact that the total synthesis of $\mathbf{1}$ and $\mathbf{2}$ have been recorded in the literature for no less than seven times since 1995 [2-8]. Due to the popularity of syringolides, attention had also been placed on secosyrin and syributins and their syntheses were also reported [5,9]. Noteworthy is that most of the literature methods leading to syringolides nonetheless suffered the same low yield problem as a result of the final cyclization step. For this reason, we devised our own program [10] directed to the preparation of 1 and 2 after we had secured a convenient and efficient entry to secosyrin 1 (3), secosyrin 2 (4), syributin 1 (5) and syributin 2 (6) [11]. Our general strategy to be engaged in the synthesis of compounds 1, 2, 3, 4, 5 and $\mathbf{6}$, as well as a related molecule sphydrofuran (7) is depicted in Scheme 1. As can be seen, 3-tri- $n$ butylstannylfuran $(\mathbf{8})$ [11,12] was utilized to assemble the chiral butenolide $\mathbf{9}$, whose acetonide protecting group was removed before being allowed to undergo a triethylamine-induced intramolecular Michael cyclization to provide a diastereomeric mixture $\mathbf{1 0}$ and 11. [11] The $(R, S, R)$-diastereomer 11 eventually led to $\mathbf{3}$ and $\mathbf{4}$ via routine functional group transformations, while the $(S, S, R)$-isomer served as the starting material for sphydrofuran (7) and its furan metabolite 12. [11] The syributins were obtained from butenolide 9 in a more straightforward manner. [11] Scheme 2 illustrates our own synthesis of syringolides 1 and 2 [10]. The introduction of an $\alpha$-keto group to $\mathbf{9}$ in the quest of $\mathbf{1 3}$ and $\mathbf{1 4}$ was accomplished by adopting an elegant procedure elaborated by Jefford and co-workers [13], which was used previously by Honda in his own syringolide synthesis [5]. After much experimentation, we finally uncovered that $10 \% \mathrm{HF}$ in $\mathrm{MeOH}$ efficiently converted 13 and 14 to 1 and 2, respectively [10].

In order to prepare $\mathbf{1}$ and $\mathbf{2}$ in good yields, a very short silica gel column and flash chromatographic conditions were eminently essential due to the instability of the syringolides on silica gel. Indeed, when longer chromatographic time was used during the purification of $\mathbf{1 3}$, the known side-product 15 [5-7] was instead isolated in 60\% yield (Scheme 3) [10]. To our surprise, the acetal in 15 was able to open and cyclize again in the presence of $p \mathrm{TsOH}$, furnishing $\mathbf{1}$ in a relatively good yield [10]. This maneuver therefore offers an alternative synthetic route for both $\mathbf{1}$ and $\mathbf{2}$.

\footnotetext{
* Invited Lecture presented at the 21st IUPAC International Symposium on The Chemistry of Natural Products (ISCNP-21), Beijing, China, 11-16 October 1998, pp. 1025-1166.

$\dagger$ Corresponding author.
} 


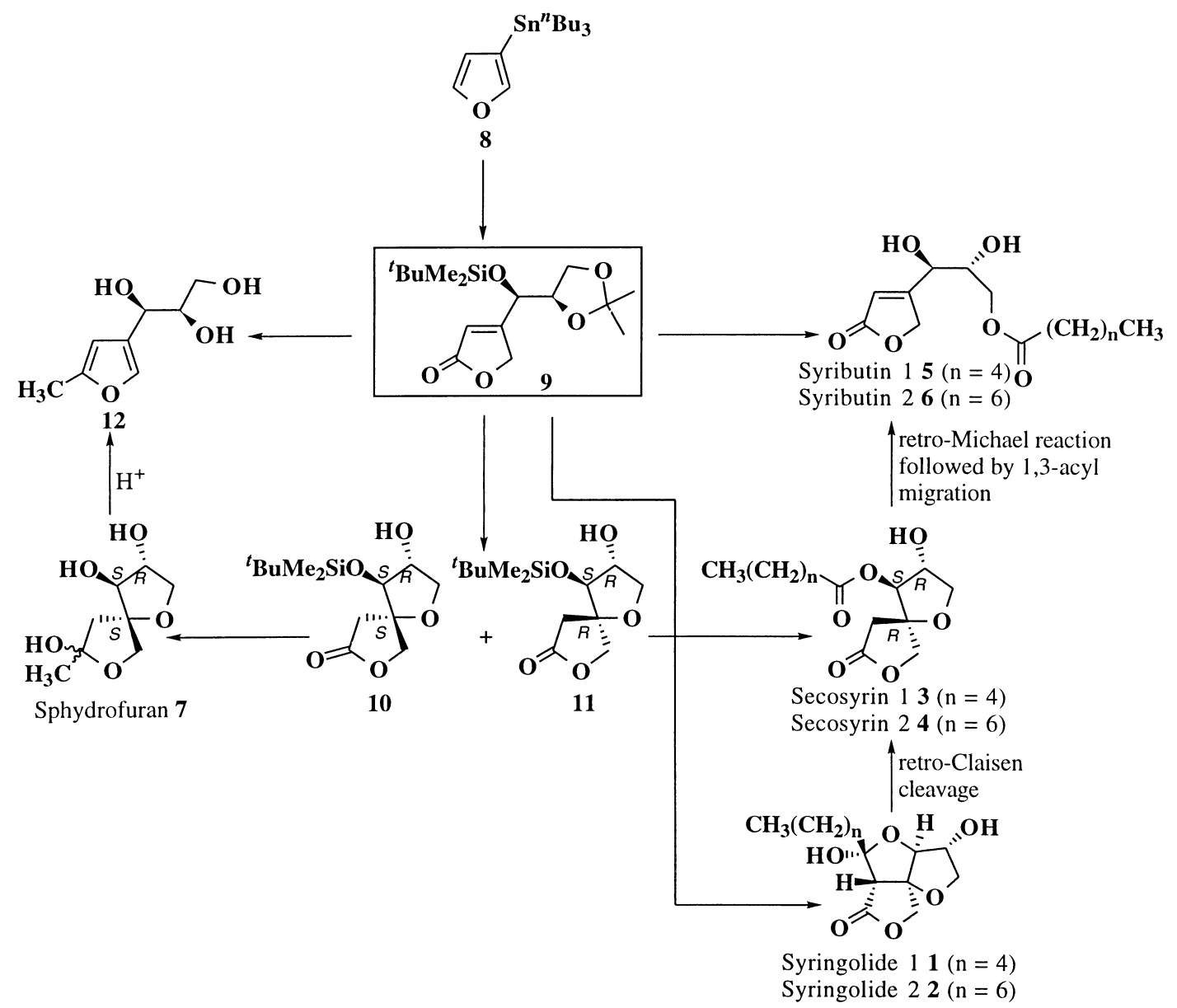

1. $\mathrm{Bu}_{2} \mathrm{BOTf}$

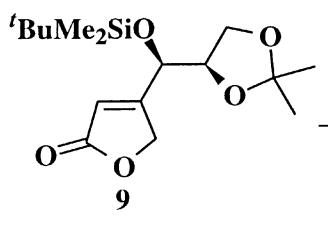

${ }^{i} \operatorname{Pr}_{2} \mathrm{NEt}$

$\mathrm{Me}\left(\mathrm{CH}_{2}\right)_{\mathrm{n}} \mathrm{CHO}$

THF, $-78^{\circ} \mathrm{C}$

2. Dess-Martin

periodinate

$\mathrm{CH}_{2} \mathrm{Cl}_{2}$

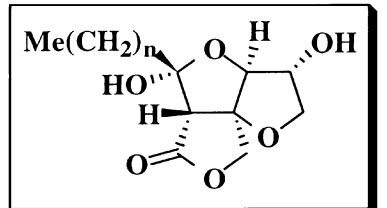

$1(n=4) 56 \%$

$2(n=6) 52 \%$

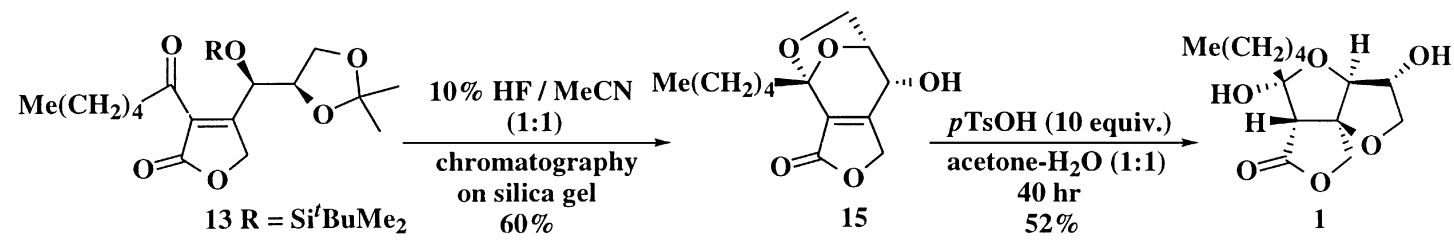

Our use of furans as precursor has also been applied to the synthesis of sesquiterpenoid lactones, of which 11,13-dihydrotubiferin (16) is a good example [14]. The synthetic pathway directing to $\mathbf{1 6}$ is illustrated in Scheme 4. 3-Methyl-4-trimethylsilylfuran (17) was chosen as the starting material for the synthetic program. 


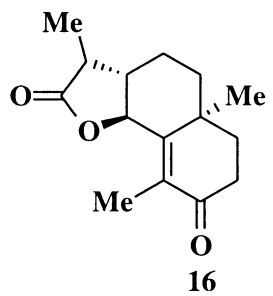

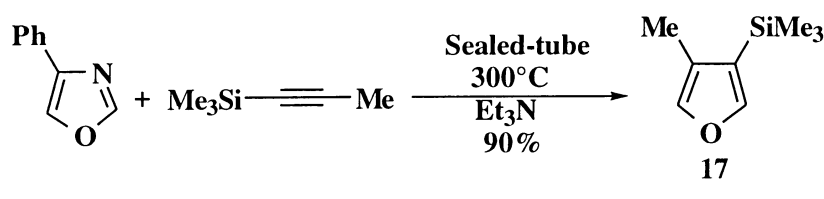

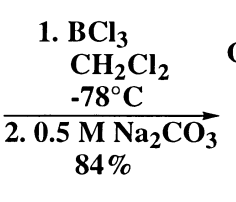<smiles>Cc1cocc1B1OB(c2cocc2C)OB(c2cocc2C)O1</smiles>

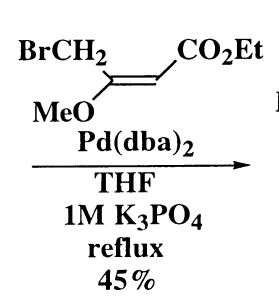<smiles>CCOC(=O)/C=C(/Cc1cocn1)O[Na]</smiles>
19<smiles>CCOC(=O)CCC(=O)Cc1coc(C)c1OCC(C)C</smiles>

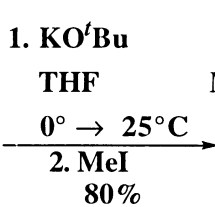
$80 \%$<smiles>CCOC(=O)C(C)C(=O)Cc1cocc1I</smiles>

21

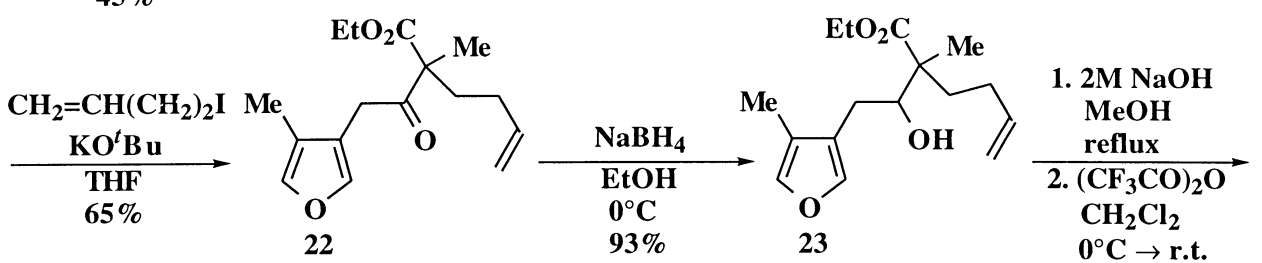

3. $1 \mathrm{M} \mathrm{NaOH}$<smiles>C=CCCC1(C)C(=O)c2occ(C)c2CC12OCCO2</smiles>

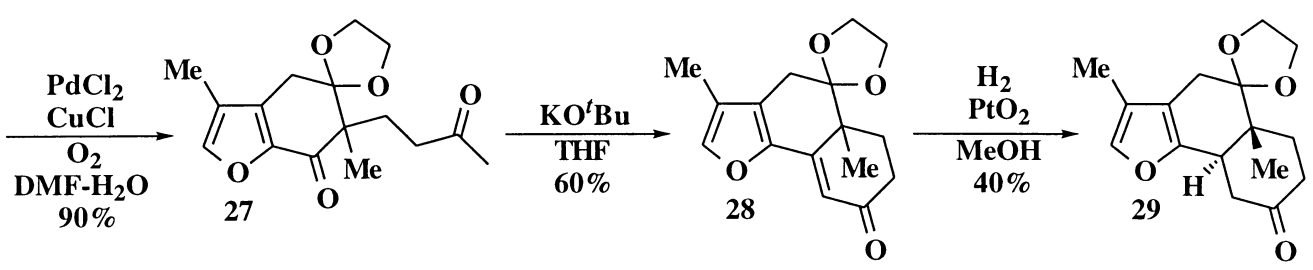

The 3,4-disubstituted furan 17 was prepared through a Diels-Alder and retro-Diels-Alder route by starting from 4-phenyloxazole and 1-trimethylsilyl-1-propyne. The trimethylsilyl group of $\mathbf{1 7}$ was expected to lead to an ipso-mode electrophilic aromatic substitution because of the silicon $\beta$-directing effect [15]. By employing our own silicon-boron protocol for the preparation of 3,4-disubstituted furans [16], furan 17 was accordingly converted through boroxine 18-19. The methyl enol ether 19 was hydrolyzed to form the ketoester 20, which smoothly went through two consecutive alkylation steps, furnishing 22. We found that the keto group of $\mathbf{2 2}$ must be reduced before the standard Friedel-Crafts acylation procedure. Thus, sodium borohydride reduction was followed by subsequent saponification and acylation. The resulting hydroxyketone $\mathbf{2 4}$ was oxidized to afford the cyclohexane-1,3-dione $\mathbf{2 5}$, which was selectively protected to provide $\mathbf{2 6}$. A Wacker oxidation process transformed the alkene $\mathbf{2 6}$ to the diketone $\mathbf{2 7}$, which was subjected to an aldol cyclization condition to lead to the desired tricyclic $\mathbf{2 8}$, whose $\mathrm{ABC}$ ring skeleton matches that of $\mathbf{1 6}$. Catalytic hydrogenation of $\mathbf{2 8}$ over the Adams platinum 
catalyst afforded 29, which will be a pivotal intermediate in our synthetic assault toward 11,13dihydrotubiferin (16). In our original design, the furan ring of 29 will serve as a latent lactone functionality [17]. A unique feature of our synthetic plan is the construction of B Ring and A Ring in the presence of the furan ring. This $\mathrm{C}$ Ring $\rightarrow \mathrm{BC}$ Ring $\rightarrow \mathrm{ABC}$ Ring approach is exemplified by the two cyclization steps as shown in Scheme 4, i.e. hydroxyester $\mathbf{2 3}$ to hydroxyketone $\mathbf{2 4}$, as well as diketone $\mathbf{2 7}$ to enone 28. To our best knowledge, most of the literature synthetic methods [18] for furanoeudesmanes have concentrated mainly on the initial construction of A Ring and/or B Ring before either the furan ring or lactone ring (Ring C) construction.

The total synthesis of $\mathbf{1 6}$ is still in progress, and so are several other sesquiterpenoid furanoeudesmanes [19].

\section{ACKNOWLEDGEMENT}

We would like to thank the Research Grants Council (Hong Kong) for financial supports (CUHK 77/93E, CUHK 296/94P and CUHK 450/95P). A Direct Grant (Project ID 2060091), administered by the Chinese University of Hong Kong, is also gratefully acknowledged.

\section{REFERENCES}

1 (a) N. T. Keen, R. I. Buzzell. Theor. Appl. Genet. 81, 133 (1991). (b) N. T. Keen, S. Tamaki, D. Kobayashi, D. Gerhold, M. Stayton, H. Shen, S. Gold, J. Lorang, H. Thordall-Christensen, D. Dahlbeck, B. Staskawicz. Molec. Plant-Microbe Interact. 3, 112 (1990). (c) S. L. Midland, N. T. Keen, J. J. Sims, M. M. Midland, M. M. Stayton, V. Burton, M. J. Smith, E. P. Mazzola, K. J. Graham, J. Clardy. J. Org. Chem. 58, 2940 (1993). (d) S. L. Midland, N. T. Keen, J. J. Sims. J. Org. Chem. 60, 1118 (1995).

2 J. L. Wood, S. Jeong, A. Salcedo, J. Jenkins. J. Org. Chem. 60, 286 (1995).

3 S. Kuwahara, M. Moriguchi, K. Miyagawa, M. Konno, O. Kodama. Tetrahedron Lett. 36, 3201 (1995); S. Kuwahara, M. Moriguchi, K. Miyagawa, M. Konno, O. Kodama. Tetrahedron 51, 8809 (1995).

4 J. P. Henschke, R. W. Richards. Tetrahedron Lett. 37, 3557 (1996).

5 T. Honda, H. Mizutani, K. Kanai. J. Org. Chem. 61, 9374 (1996).

6 J. Ishihara, T. Sugimoto, A. Murai. Synlett 33 (1996); J. Ishihara, T. Sugimoto, A. Murai. Tetrahedron 53, 16029 (1997).

7 C.-M. Zeng, S. L. Midland, N. T. Keen, J. J. Sims. J. Org. Chem. 62, 4780 (1997).

8 H. Yoda, M. Kawauchi, K. Takabe, K. Hosoya. Heterocycles 45, 1895 (1997).

9 C. Mukai, S. M. Moharram, M. Hanaoka. Tetrahedron Lett. 38, 2511 (1997); C. Mukai, S. M. Moharram, S. Azukizawa, M. Hanaoka. J. Org. Chem. 62, 8095 (1997).

10 P. Yu, Q.-G. Wang, T. C. W. Mak, H. N. C. Wong. Tetrahedron 54, 1783 (1998).

11 P. Yu, Y. Yang, Z. Y. Zhang, T. C. W. Mak, H. N. C. Wong. J. Org. Chem. 62, 6359 (1997).

12 Y. Yang, H. N. C. Wong. J. Chem. Soc., Chem. Commun. 656 (1994); Y. Yang, H. N. C. Wong. J. Chem. Soc., Chem. Commun. 1723 (1992); Y. Yang, H. N. C. Wong. Tetrahedron 50, 9583 (1994).

13 C. W. Jefford, D. Jaggi, J. Boukouvalas. J. Chem. Soc., Chem. Commun. 1595 (1988).

14 F. Bohlmann, C. Zdero. Phytochemistry 21, 647 (1982).

15 S. N. Ushakov, A. M. Itenberg. Zh. Obshch. Khim. 7, 2495 (1937); Chem. Abstract. 32, $2083^{8}$ (1938) J. B. Lambert. Tetrahedron 46, 2677 (1990). J. M. White. Aust. J. Chem. 48, 1227 (1995).

16 Z. Z. Song, Z. Y. Zhou, T. C. W. Mak, H. N. C. Wong. Angew. Chem. Int. Eds Engl. 32, 432 (1993); Z. Z. Song, M. S. Ho, H. N. C. Wong. J. Org. Chem. 59, 3917 (1994); X.-S. Ye, P. Yu, H. N. C. Wong. Liebigs Ann. Chem. 459 (1997).

17 H. Ishii, T. Tozyo, H. Minato. J. Chem. Soc (C) 1545 (1966); F. Kido, K. Tsutsumi, R. Maruta, A. Yoshikoshi. J. Am. Chem. Soc. 101, 6420 (1979).

18 A. Ojida, F. Tanoue, K. Kanematsu. J. Org. Chem. 59, 5970 (1994); A. Chakraborty, G. K. Kar, J. K. Ray. Tetrahedron 53, 2989 (1997); K. Tatsuta, S. Yasuda, K.-i. Kurihara, K. Tanabe, R. Shinei, T. Okonogi. Tetrahedron Lett. 38, 1439 (1997).

19 C. H. Brieskorn, P. Noble. Phytochemistry 22, 187 (1983); A. Ulubelen, N. Gören. J. Nat. Prod. 49, 1104 (1964); H. Hikino, Y. Hikino, I. Yosioka. Chem. Pharm. Bull. 12, 755 (1986). 